\title{
Managing Information Systems Textbooks: Assessing their Orientation toward Potential General Managers
}

\author{
Paul H. Rosenthal and L. Jane Park \\ California State University, Los Angeles, California
}

\author{
prosent@calstatela.edu, ipark@calstatela.edu
}

\begin{abstract}
This paper is an assessment of the topical coverage of current Managing Information Systems (MIS) textbooks. The MIS course is normally required of all undergraduate and graduate business majors, and therefore is their primary education in the use of IS/IT in the modern technologyoriented organization. However, the MIS textbooks researched do not attempt IS/IT management fluency. They do not even fully answer the questions normally asked by management and users during the justification and implementation of modern technology-oriented enterprise applications.

The primary author has been teaching IS/IT courses for IS professionals and for users and managers for almost fifty tears. What has changed since that time? Not as much as should have happened in the education of line and staff personnel who work in organizations with critically important IS/IT enterprise applications. Early courses for users and managers were remarkably similar to our current MIS courses. This paper, therefore, suggests a significant change in content of MIS texts from primarily encompassing technology sections covering personal productivity applications, systems development methods, and infrastructure to presenting much more detail on user and management topics including modern enterprise level applications (e.g. transaction processing systems), privacy and security, feasibility studies, and the justification of IS/IT systems.
\end{abstract}

Does our IS education approach the ever-present user and CIO questions such as:

- Why will it cost so much and take so long?

- How can I be sure this will be one of the $50 \%$ that succeed rather than the $50 \%$ that fail?

It does not. However, it is far beyond the scope of this paper to discuss all the shortcomings in the education of users and managers and how it seems to have happened; therefore the focus is on only two critical areas, enterprise level operational applications and the justif ication of these applications. The paper closes by presenting an analys is of the topical coverage of several popular

Material published as part of this publication, either on-line or in print, is copyrighted by the Informing Science Institute. Permission to make digital or paper copy of part or all of these works for personal or classroom use is granted without fee provided that the copies are not made or distributed for profit or commercial advantage AND that copies 1) bear this notice in full and 2) give the full citation on the first page. It is permissible to abstract these works so long as credit is given. To copy in all other cases or to republish or to post on a server or to redistribute to lists requires specific permission and payment of a fee. Contact Publisher@InformingScience.org to request redistribution permission.
MIS texts. Only four of the ten texts analyzed exceed $50 \%$ user and management-oriented information. They give only minimal information on enterprise operational applications and include no information on the justification of these applications. There are recommendations for improving orientation toward modern line and staff manager's know ledge requirements. 
Key Words: MIS textbooks, enterprise information systems, operational information systems, transaction processing systems, justification of IS/IT systems.

\section{Introduction}

It is a generally accepted belief that modern technology oriented enterprises, at least in the developed economies, are critically dependant on information technology based systems. This dependence involves two fundamental areas: the need for information systems to support the management of complex organizations, and the need for information systems to support the operations of information oriented functions and enterprises. For example, a survey of IT management (Caldwell, 1997, p. 100) indicated that CEOs and other top managers who are comfortable with technology initiate one third of the IT projects in the ir organizations while those who are not initiate fewer than $15 \%$. Based on this need for information systems competence, almost all business undergraduate and graduate degrees require a Managing Information Systems (MIS) course.

However competency is not enough. Quoting from the Committee on Information Technology Literacy, National Research Council report (National Research Council, 1999):

Generally, "computer literacy" has acquired a "skills" connotation, implying competency with a few of today's computer applications, such as word processing and e-mail. Literacy is too modest a goal in the presence of rapid change, because it lacks the necessary "staying power." As the technology changes by leaps and bounds, existing skills become antiquated and there is no migration path to new skills. A better solution is for the individual to plan to adapt to changes in the technology. This involves learning sufficient foundational material to enable one to acquire new skills independently after one's formal education is complete.

This requirement of a deeper understanding than is implied by the rudimentary term 'computer literacy' motivated the committee to adopt 'fluency' as a term connoting a higher level of competency.

Fluency with information systems and technology requires three kinds of knowledge: contemporary skills, foundational concepts, and intellectual capabilities. Our MIS texts lack several key foundations concepts, as discussed in this paper.

MIS text books are specifically aimed at future business managers and users. Quoting from Martin, Brown, DeHayes, Hoffer, \& Perkins (2005, p. xvii):

The purpose of this book is to prepare advanced management students, both undergraduate and graduate, to be effective managers within organizations that are expected to grow increasingly dependant on information technologies.

MacDonald and Swearingen (1989) in the ir survey of MIS texts state that:

The preponderance of material in the typical textbook presents coverage of technology and not coverage of management issues. The lack of textbook coverage of the "key issues in MIS" suggests that coverage of these issues in the classroom depends upon the ability and willingness of the individual faculty member to assemble materials to supplement the text, and therefore may be insufficient for a given undergraduate.

This emphasis on technology and the knowledge needed by IS professions still hold today, based on the survey in this paper. Therefore, the current MIS texts should provide more information on and fluency with the key IS/IT management concerns of current and future business managers. 


\section{Management and User Information Systems Knowledge Requirements}

Based on over thirty years of consulting experience by the authors, and a recent survey of business majors enrolled in MIS courses, the following questions cover some of the knowledge areas required for the level of understanding needed for intelligent management, review and approval of significant IS development projects and IT infrastructure and operations.

1. What will the system do for us?

2. How does it work?

3. Why does it cost so much?

4. Why does it take so long?

5. Since over 50\% of major IS projectsfail, what are you going to do to make this one successful?

Wager, Lee, \& Glaser's text (2005) presents a different approach to user knowledge requirements.

\section{"Senior Management Responsibilities}

- Ensuring that the organization has an IT strategy

- Balancing the perspectives of users and IT

- Establishing processes for budgeting, acquiring and implementing applications and infrastructure

- Ensuring that IT purchases conform to policies and procedures

- Developing and modifying the responsibilities of IT and users

- Ensuring that IT applications and activities conform to relevant regulations and internal controls

- Encouraging IT experimentation

\section{IS User Responsibilities}

- Understanding the IT activities that support their function

- Ensuring that the goals of IT initiatives reflect the function's needs

- Developing specifications for IT projects

- Providing feedback to IT on implementation issues, application enhancements and IT support

- Ensuring that applications function properly

- Participating in developing the IT agenda and priorities"

Charts 1 and 2 present the results of a survey of MIS students during the last week of their MIS course at CSULA that asks how important is knowledge in several key areas covered in most MIS and management theory books. Detailed results of the survey are presented in the appendix.

In general, MIS students believe all of management oriented IS knowledge areas shown are important, except that cost/benefit analysis is slightly more important, and that graduate students believe that project management dominates all other knowledge areas.

Do the current MIS textbooks cover these areas of knowledge at an adequate level? As shown in section five of this paper and based on the authors teaching experience, most do not! They equally emphasize the potential general managers knowledge areas and the potential IS professionals know ledge areas while almost ignoring cost/benefit analysis. 


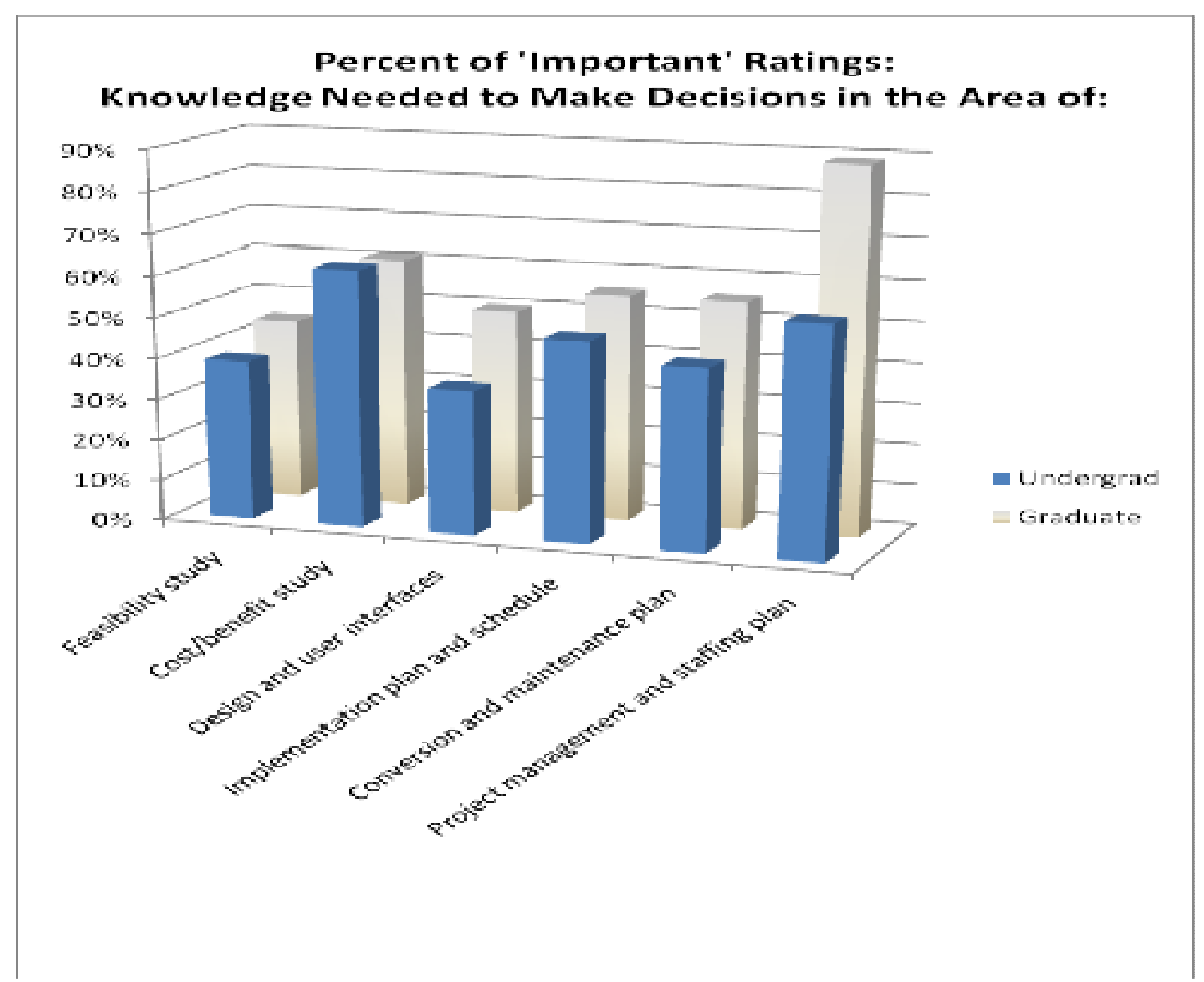

\section{Chart 1: Survey of MIS Students I}

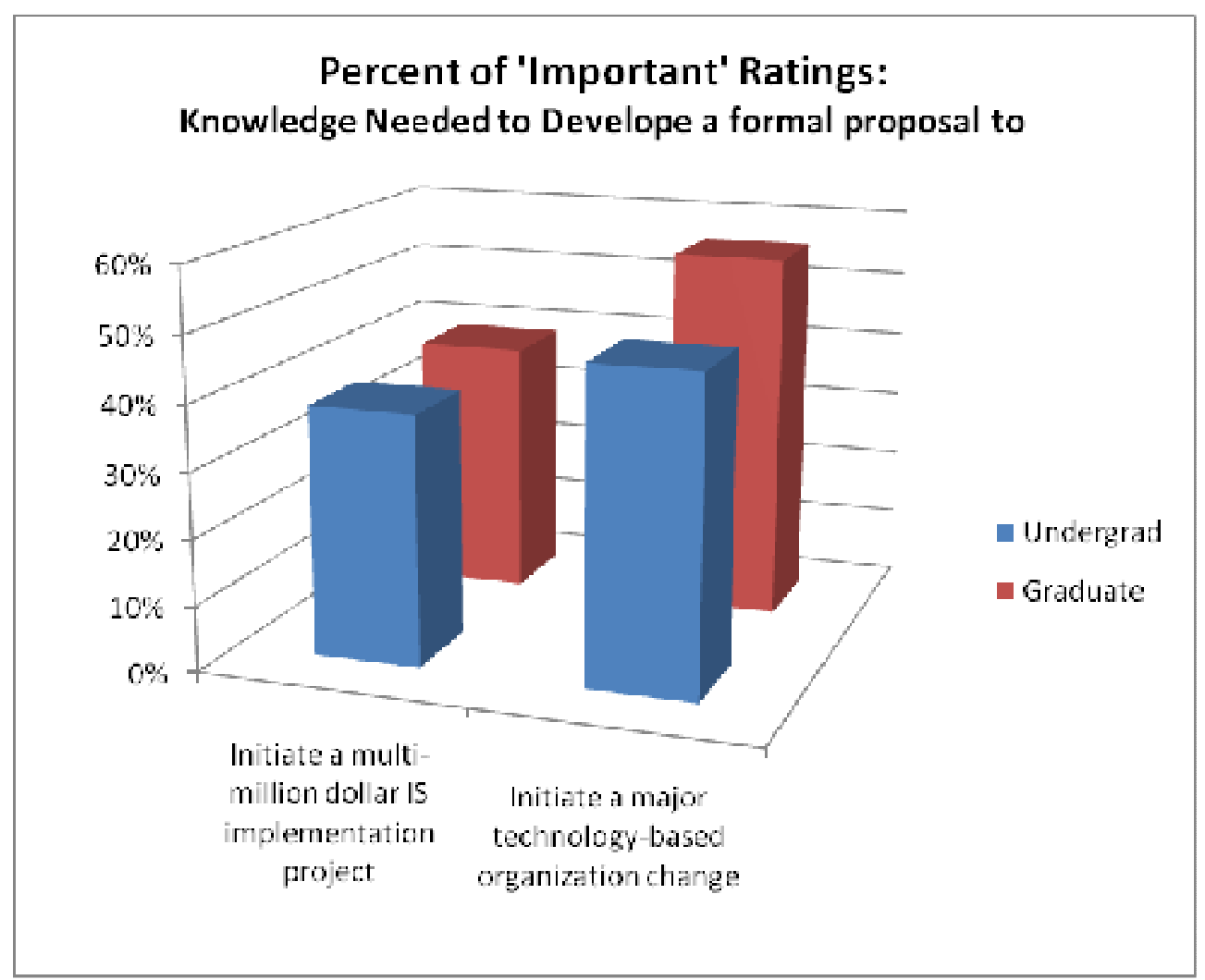

Chart 2: Survey of MIS Students II 
This paper therefore first outlines the core scope of the IS/IT knowledge needed by general managers based primarily on the questions they raise during planning and review meetings, second a description and structure of enterprise and transaction processing systems, third an analys is of the emphasis of several popular MIS texts, and closes by presenting recommendations to improve their balance by substantially increasing their coverage of Enterprise and Transaction Processing Systems (TPS) and of IS/IT economics and justification

\section{Structure of Enterprise Application Systems}

Enterprise level operations oriented applications are the core of information and the technology systems' (IS/IT) impact on organizations. In the typical medium to large business organization, they constitute the majority of IS/IT funding requirements, sometimes as much as $80 \%$. Transaction Processing Systems applications (TPS) are also the core of information systems impact on IS/IT employment; due to the number of clerical workers often involved, they frequently constitute the majority of IS/IT project funding requirements. They are also the public's contact with IS in stores, banks and for the millions of white collar workers at work.

A typical MIS text's view of the structure of enterprise systems is illustrated by Figure 1 extracted from Laudon and Laudon's $10^{\text {th }}$ edition text (Laudon \& Laudon, 2007, p. 60).

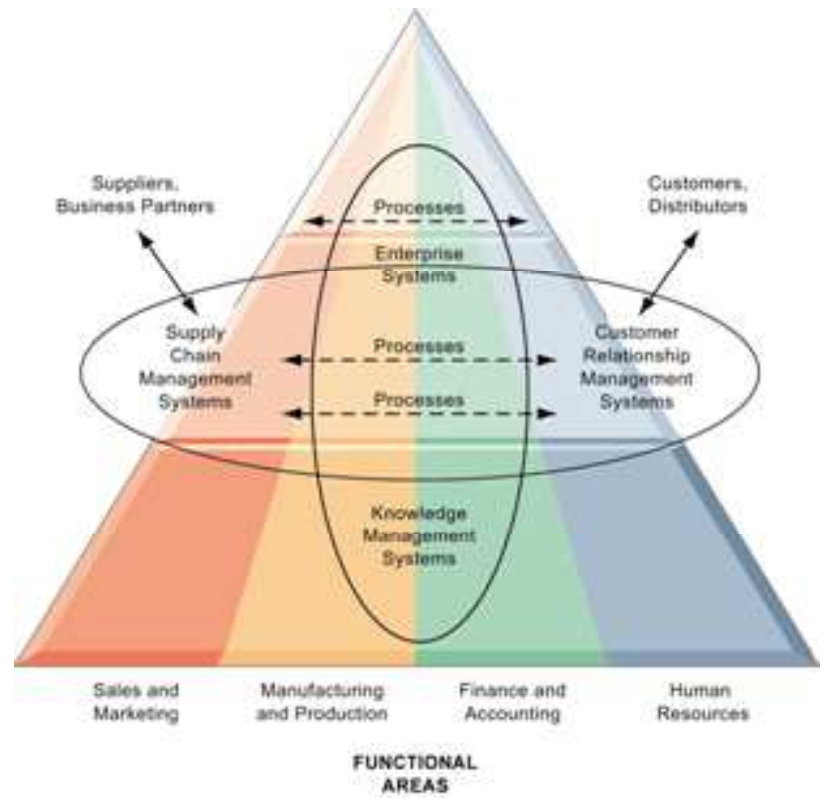

Figure 1: Enterprise Application Architecture

This view, while interesting, is not detailed enough for proper understanding of the types and relationships among operational, decision support, and personal productivity applications as might be shown in Figure 2. 


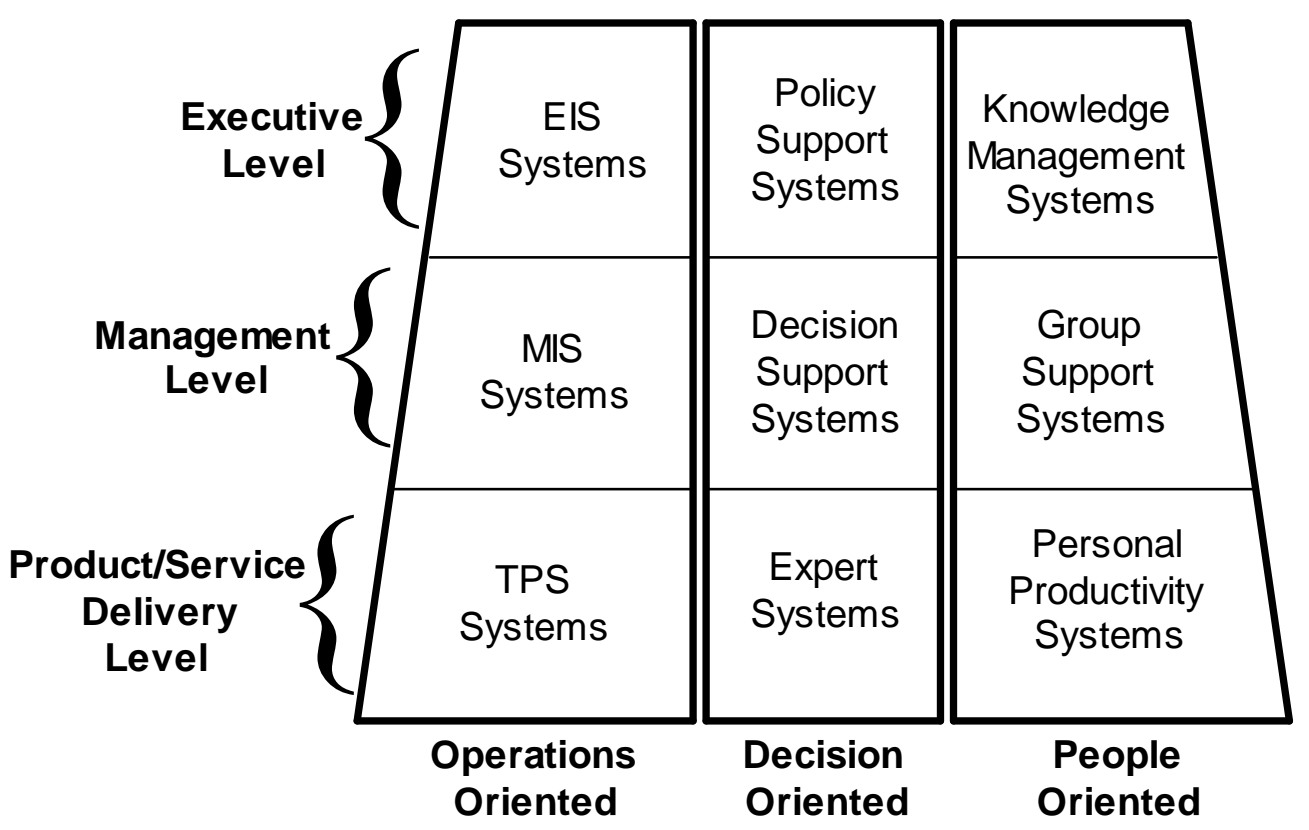

Figure 2: Enterprise Applications Classification Chart

A significant description of each type of system should include the usage, benefits and economics. A second level chart of the Operations Oriented Systems structure section of Figure 2 follows in Figure 3.

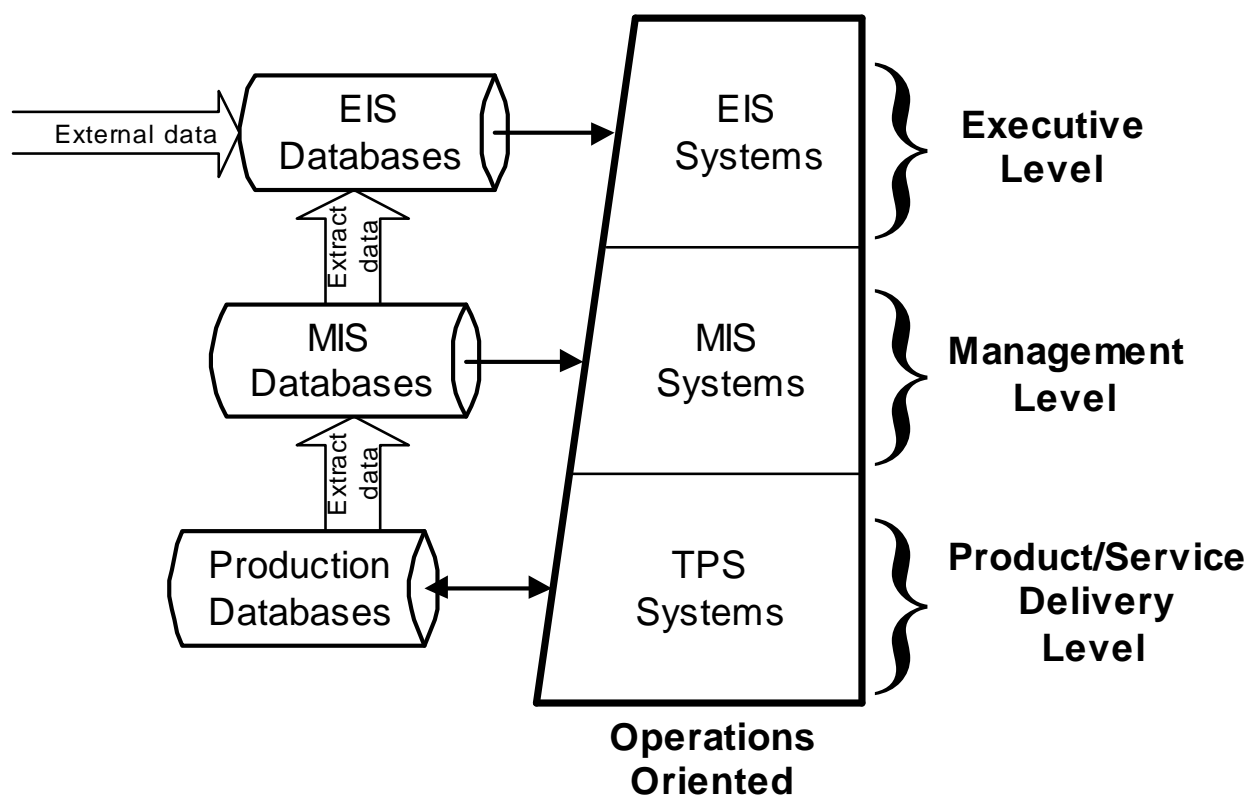

Figure 3: Operations Oriented Enterprise Systems Structure 
A description of the extraction and summarization processes involved in moving from the detailed operational data to the management and executive data bases is needed in the texts to clarify the roles of MIS and EIS applications.

\section{Transaction Processing Systems}

Transaction Processing Systems applications (TPS) make up the majority of administration oriented multi-million dollar Enterprise Systems projects. They are however given little attention in MIS and systems analysis and design textbooks perhaps due to their complexity.

Figure 4 is from Turban, Leidner, \& Wetherbe's MIS textbook (2008, p. 263). It represents a gross simplification of the scope and complexity of TPS oriented Enterprise Systems.

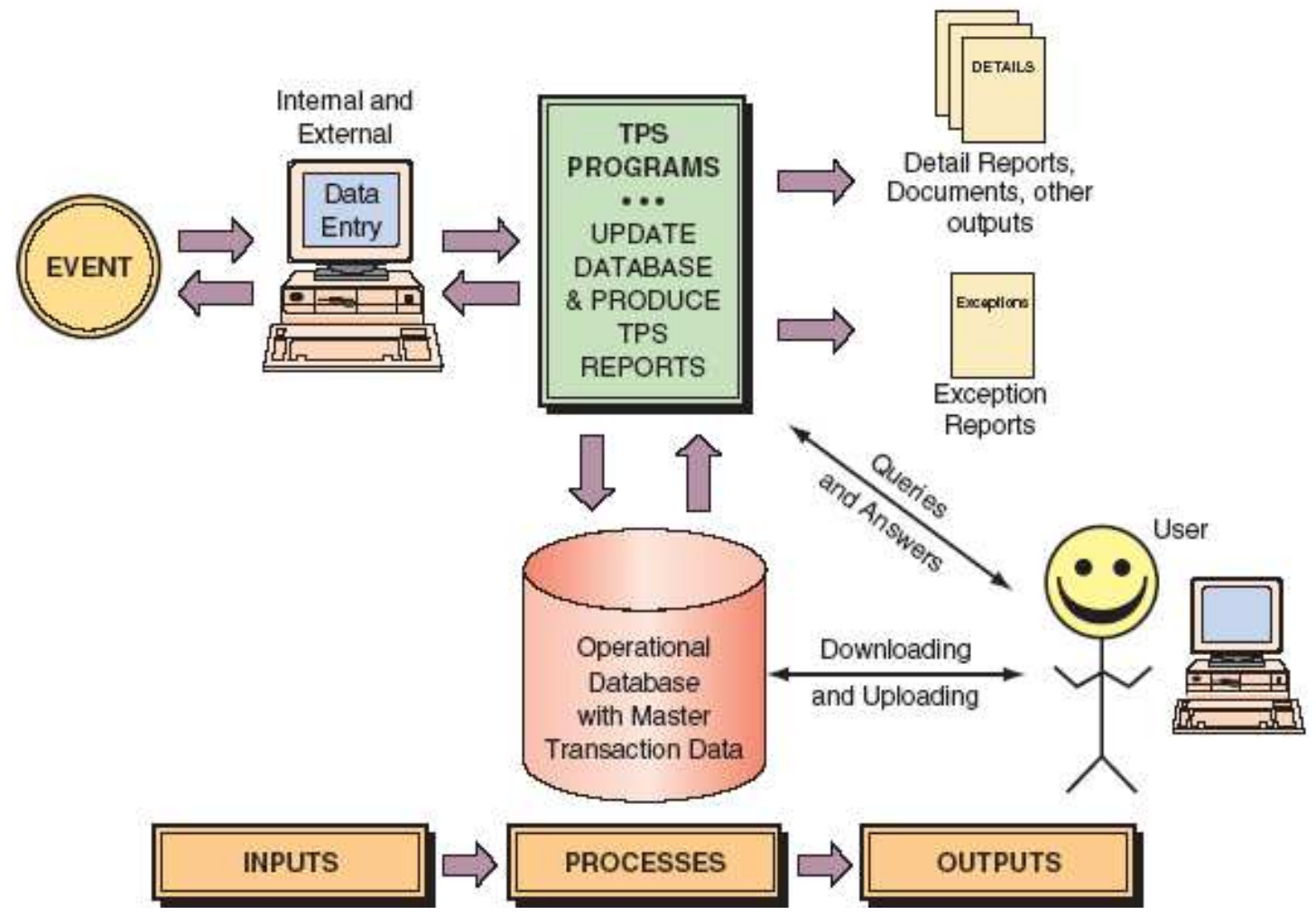

Figure 4: TPS System Scope from Turban, Leidner, \& Wetherbe textbook

Figure 5 presents the typical overall scope of enterprise level operations-oriented applications processing. It shows the interrelationships of core TPS online and batch processing with its dependant MIS, DSS, ESS, and interfacing systems. In fact, successful implementation of largescale TPS systems requires the integrated logical and physical level design and implementation of all the elements shown. Perhaps its time for Managing Information Systems textbooks to present the true scope and complexity of the modern integrated operations oriented application processing shown in Figure 5. 


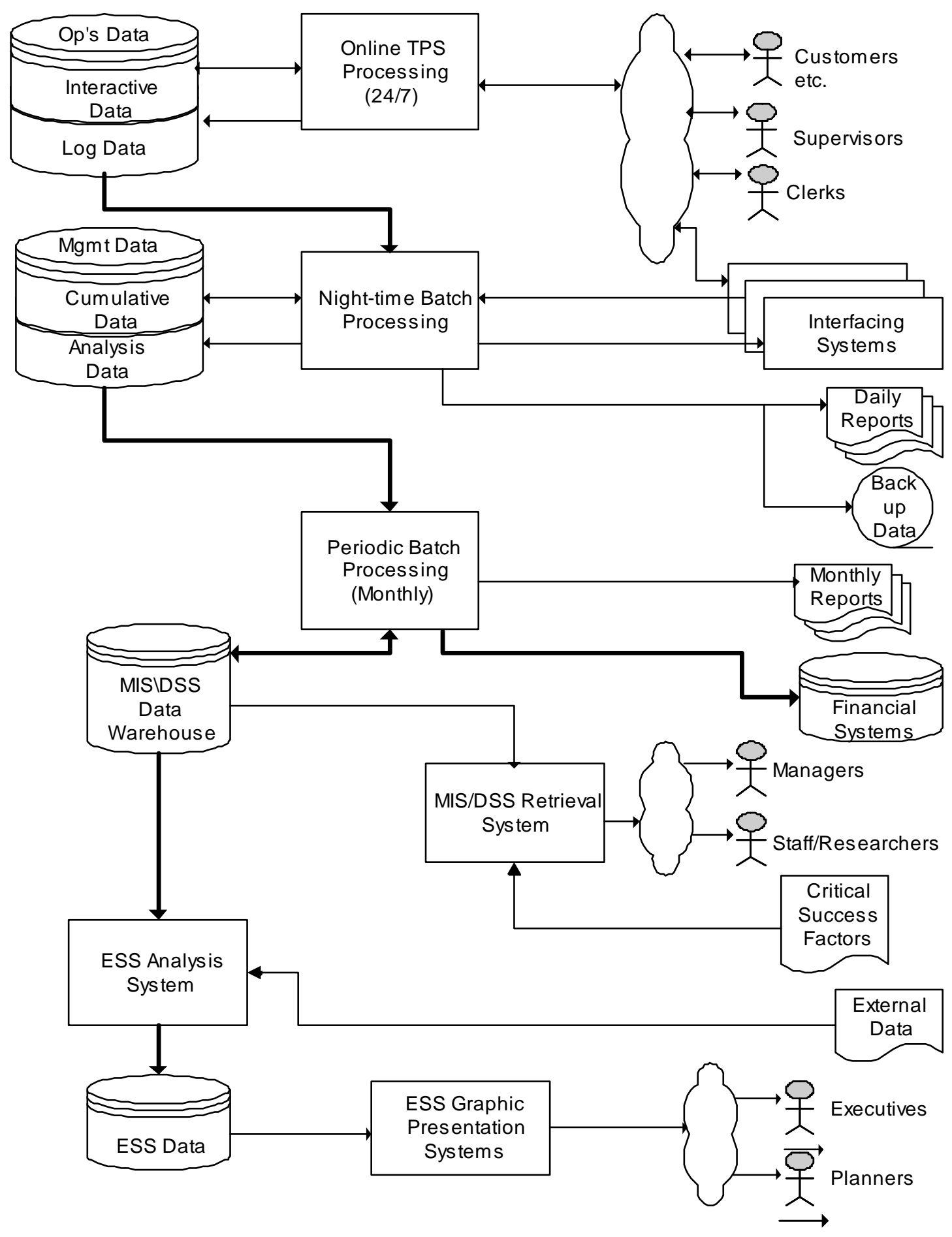

Figure 5: Structure of Enterprise Operations-Oriented Processing 


\section{Justification of Information Systems}

Our MIS texts ignore the justification and cost/benefit analys is of enterprise information systems. For example, Martin et al.'s text (popular for MBA courses) has no entry in its index for justification, pricing, or cost of information systems. A basic overview of both the managers role of system justification and the IS professionals role of software cost estimating should be included.

- Scope of the Justification of Enterprise Systems

Investments in major enterprise (mission critical) information systems often involve budgets in the eight figure range. They must be supported by a multi-year strategic plan consisting of individual short-term (less than a year) tactical plans. Two methodologies follow. The first is a policy statement adapted from OMB Directive M-97-02 (Raines, 1996); the second is a model for investment justification from a paper on IT investment strategy (Gunasekaran, Love, Rahimi, \& Mie le 2001, p. 354) as seen in Figure 6.

\section{Sample Information System Justification Policy}

1. support core/priority mission functions that need to be performed by the enterprise;

2. be undertaken by the requesting organization because no alternative vendor can efficiently provide the system or support the function;

3. support work processes that have been simplified or otherwise redesigned to reduce costs, improve effectiveness, and make maximum use of commercial, off-the-shelf technology;

4. demonstrate a projected return on the investment that is clearly equal to or better than alternative uses of available vendor resources. Return may include: improved mission performance; reduced cost; increased quality, speed, or flexibility; and increased customer and employee satisfaction. Return should be adjusted for such risk factors as the project's technical complexity, the organization's management capacity, the like lihood of cost overruns, and the consequences of under- or nonperformance

5. be consistent with the enterprise information architectures which: integrate work processes and information flows with technology to achieve the enterprise's strategic goals; reflect their technology vision; and specify standards that enable information exchange and resource sharing, while retaining flexibility in the choice of suppliers and in the design of local work processes;

6. reduce risk by: avoiding or isolating custom-designed components to minimize the potential adverse consequences on the overall project; using fully tested pilots, simulations, or prototype implementations before going to production; establishing clear measures and accountability for project progress; and, securing substantial involvement and buy-in throughout the project from the business functions who will use the system;

7. be implemented in phased, successive chunks as narrow in scope and brief in duration as practicable, each of which solves a specific part of an overall mission problem and delivers a measurable net benefit independent of future chunks; and,

8. employ an acquisition strategy that appropriately allocates risk between users and contractor, effectively uses competition, ties contract payments to accomplishments, and takes maximum advantage of commercial technology. 


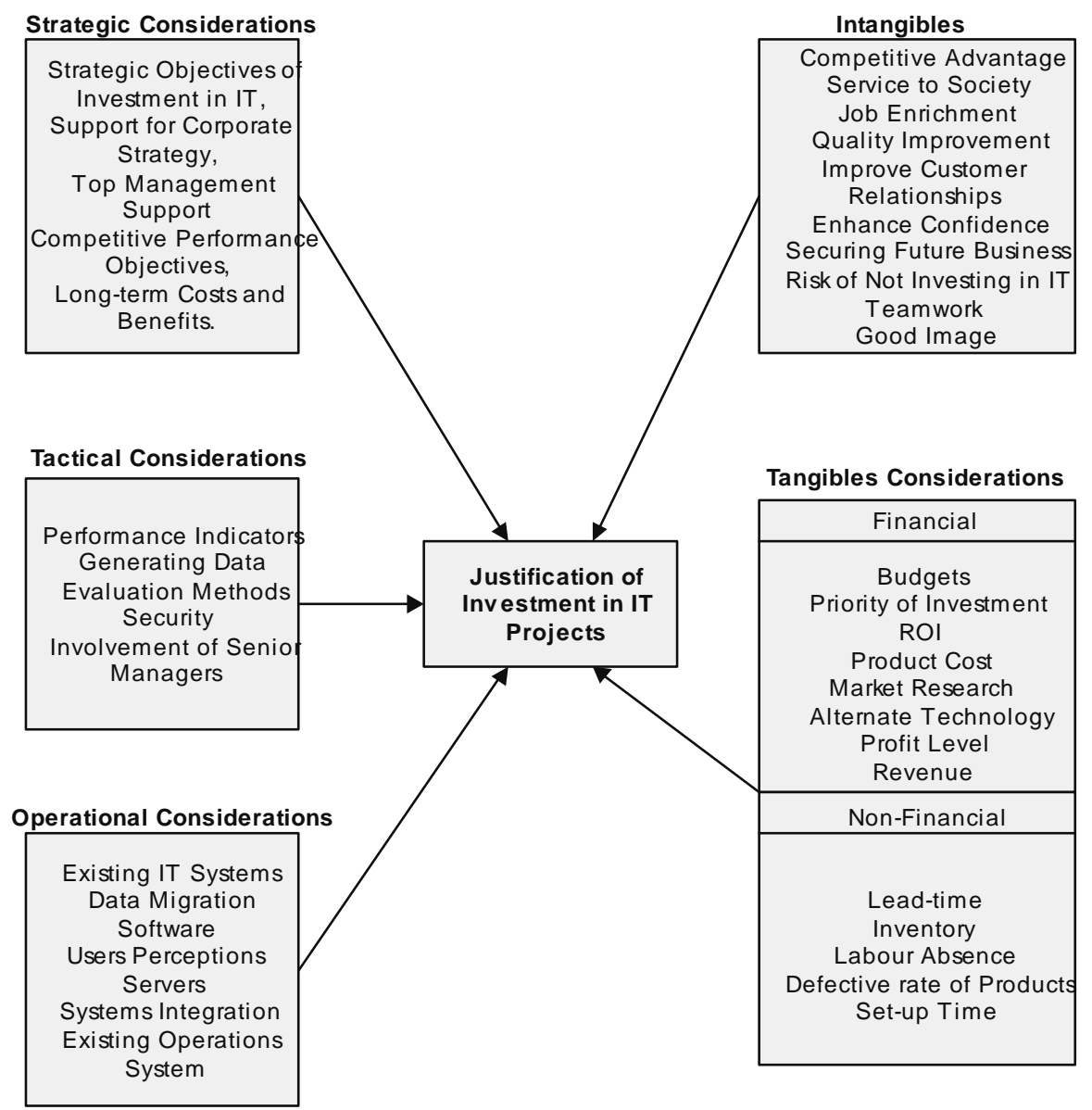

Figure 6: A Model for Investment Justification in IT Projects

Scope of the Costing of Software Implementation

The most widely available concise coverage of software project estimation can be found in Pressman's Software Engineering text (2005, Ch. 23). The core of the Function Point technique illustrated in the book involves the estimation of an application's software development cost using the type chart shown in Figure 7.

\begin{tabular}{|c|c|c|c|c|c|c|}
\hline \multirow{2}{*}{$\begin{array}{l}\text { measurement parameter } \\
\text { number of user inputs }\end{array}$} & \multicolumn{6}{|c|}{ w eighting factor } \\
\hline & $\underline{\text { count }}$ & $x$ & 3 & 4 & 6 & $=$ \\
\hline number of user outputs & & $x$ & 4 & 5 & 7 & $=$ \\
\hline number of user inquiries & & $\mathrm{X}$ & 3 & 4 & 6 & $=$ \\
\hline number of files & & $\mathrm{X}$ & 7 & 10 & 15 & $=$ \\
\hline number of ext.interfaces & & $\mathrm{X}$ & 5 & 7 & 10 & $=$ \\
\hline count-total & & & & & & \\
\hline complexity multiplier & & & & & & \\
\hline inction points & & & & & & \\
\hline
\end{tabular}

Figure 7: Estimation Worksheet: Analyzing the Information Domain 
Additional steps in the process consider the complexity of both the system, development and user environments. The process is straightforward and suitable for inclusion in an MIS textbook.

McConnell (2006) discusses several methodologies classified as follows.

\begin{tabular}{|l|l|}
\hline \multicolumn{1}{|c|}{ Popular Estimation Methods } & \multicolumn{1}{|c|}{ Better estimation Methods } \\
\hline & Estimation by analogy \\
Off-the-cuff estimation & Decomposition \\
Using expert judgment & Proxy-based estimation \\
Wide-band Delphi & Function point estimation \\
Cocomo II & The PERT Formula \\
& Putnam's Method \\
\hline
\end{tabular}

The Function Point method was selected for illustration, since it can be used during a feasibility study before most design and infrastructure decisions are made.

The OMB Investment Policy Memo (M-97-02, 1996) guidelines require this level of financial analysis. They state that project justification must:

demonstrate a projected return on the investment that is clearly equal to or better than alternative uses of available vendor resources. Return may include: improved mission performance; reduced cost; increased quality, speed, or flexibility; and increased customer and employee satisfaction. Return should be adjusted for such risk factors as the project's technical complexity, the organization's management capacity, the likelihood of cost overruns, and the consequences of under- or non-performance.

\section{MIS Textbook Coverage of Enterprise Level Applications}

The following table lists the coverage of user oriented vs. IS/IT managers oriented chapters for the major Managing Information Systems textbooks

\begin{tabular}{|c|c|c|c|c|c|c|c|c|c|}
\hline \multirow{2}{*}{\multicolumn{2}{|c|}{ Author }} & \multicolumn{3}{|c|}{$\begin{array}{c}\text { Number of User Management } \\
\text { Oriente d Chapters }\end{array}$} & \multicolumn{3}{|c|}{$\begin{array}{c}\text { Number of IS Management } \\
\text { Oriented Chapters }\end{array}$} & \multicolumn{2}{|c|}{$\begin{array}{l}\text { Business } \\
\text { Coverage }\end{array}$} \\
\hline & & $\begin{array}{c}\text { TPS \& } \\
\text { Op's } \\
\text { Appl's }\end{array}$ & $\begin{array}{c}\text { Decision } \\
\text { Appl's }\end{array}$ & $\begin{array}{l}\text { Justify/ } \\
\text { Mgmt }\end{array}$ & Proce du ral & Technology & Other & \multicolumn{2}{|c|}{ Chapters } \\
\hline \multirow{2}{*}{ Haag } & Chapters & 1 & 1 & 4 & 1 & 2 & & 6 of 9 & \multirow{2}{*}{$45 \%$} \\
\hline & Modules & & 1 & 2 & & 10 & & 3 of 13 & \\
\hline \multicolumn{2}{|c|}{ Kroenke } & 2 & 2 & 2 & 3 & 3 & & 6 of 12 & $50 \%$ \\
\hline \multicolumn{2}{|c|}{ Laudon* } & 3 & 2 & 4 & 2 & 4 & & 9 of 15 & $60 \%$ \\
\hline \multicolumn{2}{|c|}{ Mart in } & 2 & 1 & 4 & 4 & 4 & 1 & 7 of 16 & $40 \%$ \\
\hline \multicolumn{2}{|c|}{ McLeod } & 1 & 1 & 3 & 1 & 4 & 1 & 5 of 11 & $45 \%$ \\
\hline \multicolumn{2}{|c|}{ McNurlin * } & 1 & 4 & 3 & 4 & 2 & & 8 of 14 & $60 \%$ \\
\hline \multicolumn{2}{|c|}{ O'Brien * } & 3 & 1 & 4 & 2 & 4 & & 8 of 14 & $60 \%$ \\
\hline \multicolumn{2}{|l|}{$\mathrm{Oz}$} & 5 & 2 & & 3 & 4 & & 7 of 14 & $50 \%$ \\
\hline \multicolumn{2}{|l|}{ Post* } & 3 & 1 & 4 & 1 & 4 & 1 & 8 of 14 & $60 \%$ \\
\hline \multirow{2}{*}{ Turban } & Chapters & 5 & 3 & 2 & 4 & 2 & 1 & 10 of 17 & \multirow{2}{*}{$45 \%$} \\
\hline & Guides & & & & 1 & 5 & & 0 of 6 & \\
\hline
\end{tabular}

* The addition of justification and estimation material would make these texts meet the authors' recommendations.

It is the author's opinion that approximately two-thirds of the MIS texts chapters should reflect topics of interest to management students in our MIS courses. The addition of a chapter on justification and estimation, plus a detailed coverage of TPS applications would at least four of the ten texts surveyed into compliance. 
MIS textbooks applications methodology coverage is far too oriented to the functions of IS professionals rather than to the line and staff personnel of technology oriented enterprises and business functions. They currently offer

- An extensive review of hardware and systems software

- An extensive review of personal productivity software

- Extensive coverage of management and development methodologies

- A Limited coverage of operations type enterprise applications

- Almost no coverage of project justification and pricing

This coverage should be compressed to allow for the expansion of the following areas.

- Include extensive integrated coverage of TPS, MIS, and EIS applications

- Include extensive coverage of Decision, Expert, Group, Know ledge, and Personal Productivity systems in an Organizational Environment

- Include coverage in a methodology section on justification and costing of IS/IT systems and products

- Include coverage in an introductory chapter that outlines the typical budget allocation in a typical medium or large organization of the above applications benefits and costs relating to personnel, IS development, and IT operations.

In summary, the authors advocate that approximately two-third of MIS texts material should be business manager oriented.

\section{References}

Caldwell, B. (1997, March 17). Top execs take IT reins. Information Week, 100.

Gunasekaran, A., Love, P., Rahimi, F., \& Miele, R. (2001). A model for investment justification in information technology projects. International Journal of Information Management, 21, 349-364. Elsevier.

Haag, S., Cu mmings, \& M., Phillips, A. (2006). Management information systems for the information age (6th ed.). New York: McGraw-Hill Irwin.

Kroenke, D. M. (2007). Using MIS. New Jersey: Pearson Prentice Hall.

Laudon, K. C., \& Laudon, J. P. (2007). Management information systems: Managing the digital firm (10th ed.). New Jersey: Pearson Prentice Hall.

MacDonald, L. \& Swearingen (1989). Coverage of key issues in the MIS Course. CIS Educator Forum 2(4), 12-16.

Martin, E. W., Brown, C. V., DeHayes, D. W., Hoffer, J. A., \& Perkins, W. C. (2005). Managing information technology (5th ed.). New Jersey: Pearson Prentice Hall.

McConnell, S. (2006). Software estimating: Demystifying the black art. Microsoft Press.

McLeod, R., Jr., \& Schell, G. P. (2007). Management information systems (10th ed). New Jersey: Pearson Prentice Hall.

McNurlin, B. C., \& Sprague, R. H., Jr. (2006). Information systems management in practice (7th ed.). New Jersey: Pearson Prentice Hall.

National Research Council, Co mmittee on Information Technology Literacy. (1999). Being fluent with information technology. National Academies Press, http://www.nap.edu/permissions/ 
PLEASE RATE THE IMPORTANCE TO

YOU OF HAVING THE KNOWLEDGE TO MAKE DECIS IONS IN THE FOLLOWING AREAS :

\section{Undergraduate Students $\mathbf{n = 1 1 0}$}

Approval of an IS application's:

Feasibility study

Cost/benefit study

Design and user interfaces

Imple mentation plan and schedule

Conversion and maintenance plan

Project management and staffing plan

\begin{tabular}{cccccccc}
\multicolumn{2}{c}{ Important } & \multicolumn{2}{c}{ Desirable } & \multicolumn{3}{c}{ Interesting } & \multicolumn{2}{c}{ vat Rele- } \\
$\#$ & $\%$ & $\#$ & $\%$ & $\#$ & $\%$ & $\#$ & $\%$ \\
43 & $39 \%$ & 34 & $31 \%$ & 30 & $27 \%$ & 3 & $3 \%$ \\
69 & $63 \%$ & 22 & $20 \%$ & 16 & $15 \%$ & 3 & $3 \%$ \\
39 & $35 \%$ & 38 & $35 \%$ & 30 & $27 \%$ & 3 & $3 \%$ \\
54 & $49 \%$ & 30 & $27 \%$ & 20 & $18 \%$ & 6 & $5 \%$ \\
49 & $45 \%$ & 22 & $20 \%$ & 25 & $23 \%$ & 14 & $13 \%$ \\
62 & $56 \%$ & 23 & $21 \%$ & 21 & $19 \%$ & 4 & $4 \%$
\end{tabular}

Important Desirable Interesting $\begin{gathered}\text { Not Rele- } \\ \text { vant }\end{gathered}$

De velopment of a formal proposal, for executive management review, to

Initiate a mu lti-million dollar IS implementation project

Initiate a major technology-based organization change

$\begin{array}{cccccccc}\# & \% & \# & \% & \# & \% & \# & \% \\ 40 & 38 \% & 33 & 30 \% & 32 & 29 \% & 5 & 5 \% \\ 50 & 48 \% & 25 & 23 \% & 30 & 27 \% & 5 & 5 \%\end{array}$

\section{Biographies}

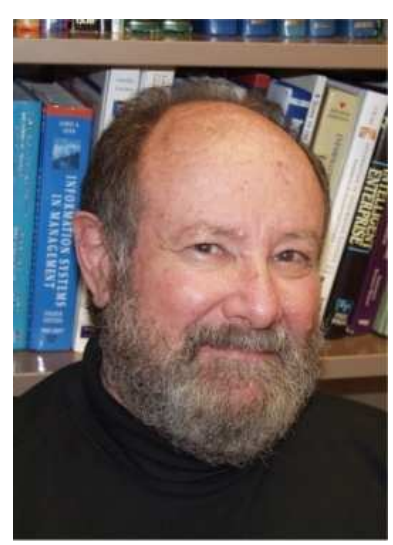

Paul H. Rosenthal is a Professor of Information Systems at California State University, Los Angeles. Dr. Rosenthal teaches a wide variety courses encompassing information systems technology and management, political economy, and systems audit and assessment He received a BS in Ed and an MA in Applied Mathematics from Temple University, an MBA from UCLA, and a DBA from USC. Prior to joining CSULA, he spent thirty six years in industry as a professional, a manager, and as a consultant. His recent research interests involve IS/IT education assessment and business continuity management. 


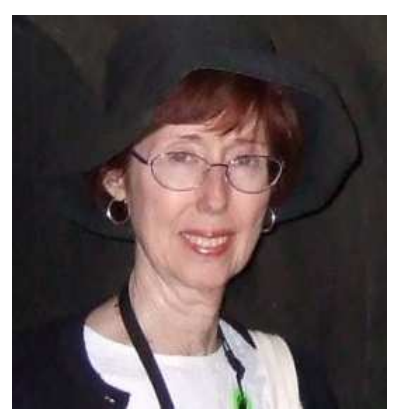

L. Jane Park is a Professor of Accounting at California State University, Los Angeles. Dr. Park teaches financial accounting and professional skills courses. She received a BS in Chemistry from the University of Texas at Austin, a Ph. D. in Chemistry from the University of Illinois at Champaign-Urbana, and a MS in Accountancy from the University of Houston, Main Campus. She also holds a Texas CPA license. She has been on the faculty at various schools in Texas and California, teaching both chemistry and accounting. Her research interests involve technology-oriented pedagogy 